\title{
Investigating the impact of the Chi-Chi earthquake on the occurrence of debris flows using artificial neural networks
}

\author{
Fi-John Chang,* Yen-Ming Chiang and Wong-Shuo Lee \\ Department of Bioenvironmental Systems Engineering, National Taiwan University, Taiwan, Republic of China
}

\begin{abstract}
:
Debris flows have caused enormous losses of property and human life in Taiwan during the last two decades. An efficient and reliable method for predicting the occurrence of debris flows is required. The major goal of this study is to explore the impact of the Chi-Chi earthquake on the occurrence of debris flows by applying the artificial neural network (ANN) that takes both hydrological and geomorphologic influences into account. The Chen-Yu-Lan River watershed, which is located in central Taiwan, is chosen for evaluating the critical rainfall triggering debris flows. A total of 1151 data sets were collected for calibrating model parameters with two training strategies. Significant differences before and after the earthquake have been found: (1) The size of landslide area is proportioned to the occurrence of debris flows; (2) the amount of critical rainfall required for triggering debris flows has reduced significantly, about half of the original critical rainfall in the study case; and (3) the frequency of the occurrence of debris flows is largely increased. The overall accuracy of model prediction in testing phase has reached $96.5 \%$; moreover, the accuracy of occurrence prediction is largely increased from 24 to $80 \%$ as the network trained with data from before the Chi-Chi earthquake sets and with data from the lumped before and after the earthquake sets. The results demonstrated that the ANN is capable of learning the complex mechanism of debris flows and producing satisfactory predictions. Copyright (C) 2009 John Wiley \& Sons, Ltd.
\end{abstract}

KEY WORDS debris flows; the Chi-Chi earthquake; artificial neural network

Received 3 January 2009; Accepted 7 May 2009

\section{INTRODUCTION}

Taiwan is situated at the junction of the Eurasian Plate and Philippine Sea Plates where earthquakes occur frequently. Resulting from the active orogenesis, the Central Mountain Range is therefore up-heaved that results in high elevations and steep slopes, and the mountain terrain is close to $70 \%$ of the island. Because of the lack of usable land, many housing units were built on the hillsides or the hills near the metropolitan areas. These highly concentrated engineering structures resulted in difficulties in soil and water conservation. This phenomenon increases the surface runoff and shortens the concentration time of peak flows during typhoon periods. Due to the special meteorological and geographical environment, people living in this island have suffered from many catastrophic disasters, such as floods and debris flows.

As compared with floods, debris flows are considered more dangerous and devastating because they typically carry large boulders and rocks that can affect or destroy structures in their paths. Because of the unique topographical and meteorological characteristics of Taiwan, the calamities caused by debris flows often happened in the past. Nevertheless, the activities of earthquakes accelerate the occurrence of debris flows due to huge amounts of sediments that are generated from earthquakes. Amongst the earthquakes that have occurred in

* Correspondence to: Fi-John Chang, Department of Bioenvironmental Systems Engineering, National Taiwan University, Taipei, Taiwan, Republic of China. E-mail: changfj@ntu.edu.tw
Taiwan, the Chi-Chi earthquake $\left(M_{\mathrm{W}}=7.6\right.$; at $23.85^{\circ} \mathrm{N}$, $120.81^{\circ} \mathrm{E}$ ), with a focal depth of $8.0 \mathrm{~km}$, was triggered by reactivation of the Chelungpu fault in central Taiwan on 21st September, 1999. This destructive earthquake caused 2400 deaths, 8373 casualties and more than US $\$ 10$ billion in damages (Lin et al., 2004) and caused serious landslides (more than 20000 landslides in an area of $2400 \mathrm{~km}^{2}$ ) in central Taiwan. Once heavy rainfalls or typhoons occur, the loose colluvium is weakened, which easily leads to a debris flow. The follow-up impact of the Chi-Chi earthquake on the debris flows is that the frequency of debris flows occurrence has significantly increased.

Debris flows are usually caused by heavy rainfall in mountainous areas and consist of various materials such as water, trees, sand, mud, soil, gravel and rocks after the collapse of hillsides. Debris flows are sometimes regarded as mudslides or landslides; however, the dynamics of a debris flow is quite different from pure landslide phenomenon. It can force faster velocities and make sudden and powerful impact that can often cause enormous destruction and damage (Chang et al., 2007b). Several factors contribute to the occurrence of debris flows, including loose deposits, steep slopes and sufficient rainfall. Debris flows that are initiated from the aforementioned sources can further grow in volume by incorporating materials in its path that therefore greatly increases its destructive power. On reaching flatter ground, the debris spread over a broad area and form the debris flow fan. 
One of the most important tasks for hydrological researchers in Taiwan is to develop a reliable model for predicting the occurrence of debris flows. Nevertheless, the mechanism of its development is not yet clearly understood. In the past, a number of studies on the evolution of debris flows were carried out by statistical analysis (e.g. Lin et al., 2006). Parts of the research focused on understanding the basic mechanisms and physical factors (Liu and Huang, 2006). However, debris flows are influenced by a range of factors, including hydrological, meteorological, geomorphologic and geological factors. The physical phenomena behind the debris flows present great complexity, high non-linearity and spatial and temporal variability. Moreover, it may be time-consuming for fully understanding all the natural processes of debris flows.

The artificial neural network (ANN) is a relatively new computational technique that is inspired by neurobiology to perform brain-like computations and has been recently accepted as an efficient alternative tool for modelling complex and non-linear hydrological systems. In general, ANN is composed of a number of interconnected processing elements (neurons) with the attractiveness of information-processing characteristics such as parallelism, noise tolerance, learning and generalization capability. They learn from examples and capture appropriate functional relationships amongst the data even if the underlying mechanisms are unknown or difficult to be recognized. The applications of ANN to various aspects of hydrological modelling have provided many promising results, including rainfall-runoff process (Dawson and Wilby, 1998; Zealand et al., 1999; Chang et al., 2007a; Chiang et al., 2007b), sediment concentration estimation (Nagy et al., 2002), landslide analysis (Kanungo et al., 2006; Lee et al., 2007; Pavel et al., 2008) and precipitation prediction (French et al., 1992; Chiang et al., 2007a). However, the application or investigation of ANN to the topic of debris flows prediction is still limited. Hence, it is necessary and important to continue the research on the applicability of the ANN models in dealing with debris flows prediction. The major goal of this study was to build a reliable ANN model for debris flows prediction and explore the impact of earthquakes on the occurrence of debris flows.

In this study, we briefly describe the study area and processes to obtain hydrological and geomorphologic factors. Next, the structure of a backpropagation network and the procedure of model training are presented. Results obtained from different training strategies are discussed in the subsequent section, and finally conclusions are drawn.

\section{STUDY AREA AND DATA ANALYSIS}

Study area

The Chen-Yu-Lan River watershed, as shown in Figure 1, was selected in the present study for investigating the debris flows hazards. It originates from the north peak of Yu Mountain, which is at an elevation of
$3910 \mathrm{~m}$, has a length of $42.4 \mathrm{~km}$ with an average slope on the order of $1 / 20$ from the riverhead to the outfall and a watershed area of about $450 \mathrm{~km}^{2}$ with a mean annual rainfall of about $3000 \mathrm{~mm}$. The watershed is located in mountainous area and most of these mountains are more than $2000 \mathrm{~m}$ in elevation, indicating a topographical characteristic of deep and narrow valley with torrential and rapid flow. There are 16 sites in tributaries of the ChenYu-Lan River (see Figure 1) that are likely to have debris flows hazards are considered in this study. A better understanding of the topographic characteristics might facilitate comprehending the concepts for predicting the potential occurrence of debris flows. The Chen-Yu-Lan River follows a major fault, the Chen-Yu-Lan Fault, which is a boundary fault dividing two major geological zones of Taiwan: the western foothills and the Hsuehshan Range (Lin and Jeng, 2000). The study area also contains other faults that are accompanied by fractured zones that could generate great topographic relief and abundant rocks that have resulted in frequent landslides and debris flows.

\section{Data collection}

To evaluate the accuracy and reliability of debris flows prediction, hourly data of observed debris flows events and potential influential factors were collected. A total of 34 storm or typhoon events with debris flows occurrence were recorded from 1985 to 2001 . It is likely that the topographic conditions and hydrological characteristics have changed after the Chi-Chi earthquake. Therefore, these data were further classified into two groups: before and after the Chi-Chi earthquake. The first group consisted of 1036 records $(1985 \sim 1998)$, including 24

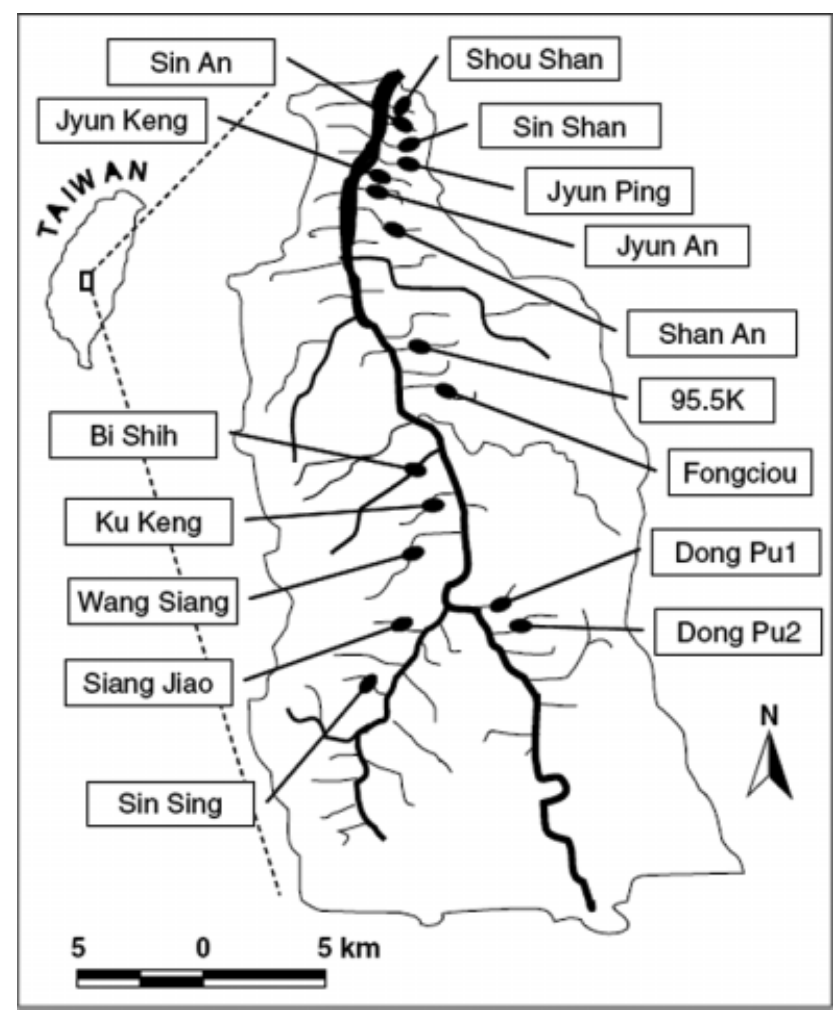

Figure 1. Location of Chen-Yu-Lan River watershed and sub-basins 
occurrences of debris flows data, and the second group consisted of 115 records $(2000 \sim 2001)$, including 21 occurrences of debris flows data. Thus, the impact of the earthquake on the occurrence of debris flows will also be discussed.

These data contain several types of information that have been identified as influential factors for the debris flows and can be divided into two basic categories, hydrological and geomorphologic factors, including (1) effective rainfall duration (ED) and effective cumulative rainfall (ER) and (2) creek length, size of subbasin area, slope and form factor (Chang and Chao, 2006; Lu et al., 2007). The hydrological data were analyzed according to the distance between rain gauges and sites of debris flows occurrences. To circumvent the difficulties in acquiring in situ data, a digital terrain model (DTM) with topographic maps $(1: 25000$ scale) was applied to calculate the geomorphologic factors in a geographic information system (GIS) environment. The pre-processing procedure has been adopted by most of the debris flows related researchers (Lin et al., 2002; Wan et al., 2008) for digitizing the map of terrain and analyzing the DTM data.

\section{Analysis of hydrological factors}

Due to the uncertainties and irregular temporal and spatial distribution of rainfall, different sites should have different rainfall, especially at a mountainous region such as the selected study area. However, the rainfall measured by ground gauging stations is generally used to represent a regional rainfall. This is unsuitable for debris flows prediction because accurate effective rainfall has been identified as one of the major forces that will initiate the instability processes for debris flows. To properly consider the influence of a storm event and the quantity of rainfall at ungauged sites, methods to estimate rainfall using observations at adjacent sites are necessary. The National Weather Service proposed the inverse distance weight method by using weights inversely proportional to the square distance between the rain gauge and the subbasin (location of debris flows). The method is fast and easy to compute, and therefore, widely used (Lu et al., 2007). Formally, the inverse distance weight method is used to estimate the rainfall value $\hat{Z}$ at location $X_{o}$, given the observed rainfall value $Z$ at specific sites $X_{i}$. The procedure is as follows:

$$
\hat{Z}\left(X_{\mathrm{o}}\right)=\sum_{i=1}^{n} \lambda_{i} Z\left(X_{i}\right)
$$

where $\lambda_{i}$ represents the weights that are calculated from the distance between the rain gauge and the sub-basin and can be defined as

$$
\lambda_{i}=\frac{f\left(d_{\mathrm{o} i}\right)}{\sum_{i=1}^{n} f\left(d_{\mathrm{o} i}\right)}
$$

where $f$ represents the inverse square ratio as shown in Equation (3):

$$
f\left(d_{\mathrm{o} i}\right)=1 / d_{\mathrm{o} i}^{2}
$$

where $d_{\mathrm{o} i}$ is the distance between $X_{\mathrm{o}}$ and $X_{i}$

ED (h) and ER (mm) are defined as follows. The ED was counted from the time (start raining) that the accumulative rainfall reached $10 \mathrm{~mm}$ to the time point (stop raining) that the accumulative rainfall was less than $10 \mathrm{~mm}$ within $24 \mathrm{~h}$. The ER was defined as a continuous rainfall from the time of starting raining to the time of occurrence of debris flows. Therefore, the ER can be calculated by using Equation (4):

$$
E R=\sum_{t=0}^{T} \alpha^{t} R_{t}
$$

where $R_{t}$ represents the actual rain at time $t$, in which $t=$ 0 refers to start raining, and $T$ represents the actual value for which $E R$ is to be calculated. Parameter $\alpha^{t}$ presents a decay coefficient that accounts for the decreasing influence of previous rainfall at time $t$ and can be defined as follows:

$$
\alpha=\sqrt{K}
$$

where $K$ represents a coefficient proposed by Fedora and Beschta (1989) that depends on the area of the sub-basin (A) and can be calculated as shown in Equation (6):

$$
K=0.881+0.00793 \ln (\mathrm{A})
$$

\section{Analysis of geomorphologic factors}

The occurrence of a debris flow is highly susceptible to the local topographical conditions. Even within the same watershed, different locations might have distinct terrain characteristics. The factors we considered in this study can be referred to previous works (Lu et al., 2007; Wan et al., 2008), that is, creek length (km), size of subbasin area $\left(\mathrm{km}^{2}\right)$, slope (degree) and form factor. The creek length is an important geomorphologic factor for predicting debris flows. It is obvious that the longer the creek, the more the deposits can be gathered together and carried down the stream. The size of the subbasin area is related to the amount of rainwater that streams into the river. A larger watershed area receives a larger amount of rainwater and yields more floods, and therefore, has a higher likelihood of inducing debris flows (Vanacker et al., 2003). The slope is an essential and important factor triggering the occurrence of debris flows, as has been identified by many researchers (e.g. Lin et al., 2004). The form factor represents the watershed characteristic that is highly related to the distribution of streamflow hydrograph. A narrow watershed has a smaller form factor, which means the streamflow hydrograph is platykurtic, whereas a circular watershed has a larger form factor, which means the streamflow hydrograph is mesokurtosis or leptokurtosis. In sum, a larger form factor of a watershed means the watershed has a larger runoff quantity in unit time than that of a 
smaller form factor. Besides, many previous studies have demonstrated that the size of the landslide area is highly related to the occurrence of debris flows. The landslide phenomenon usually provides a huge amount of soil, gravel and rocks, which is one of the major necessities for triggering debris flows.

Landslides are quite common in this watershed. Before the Chi-Chi earthquake, the landslide area was about $7.5 \times 10^{6} \mathrm{~m}^{2}$ (January 1999), but it almost tripled to $20.8 \times 10^{6} \mathrm{~m}^{2}$ (January 2000) after the earthquake (Lin et al., 2004). Since there was no abnormal storm event during this period, the abrupt increase in landslide area was most likely attributed to the Chi-Chi earthquake. Such great change in the size of the landslide area could greatly increase the probability of the occurrence of debris flows over this region, and therefore was taken into consideration in this study.

To analyze and extract the above-mentioned geomorphologic factors, the GIS tool that has been widely utilized by many researchers (Ayalew and Yamagishi, 2005; Wen and Aydin, 2005) was applied to gain the main features of each sub-basin. GIS provides a platform for data inventory and manipulation and increases the efficiency of data analysis. Table I shows the chosen geomorphologic parameters and size of landslide area of each subbasin. The red parts in Figure 2 show the size of the area segmented for data analysis in each sub-basin and values in brackets represent the ratio of landslide area to subbasin area. Basically, every sub-basin has a drainage area larger than $0.1 \mathrm{~km}^{2}$ and a slope greater than $10^{\circ}$ that has the necessary condition for triggering debris flows.

\section{APPLICATION OF DEBRIS FLOWS PREDICTION}

\section{Methodology}

An ANN consists of many simple elements/neurons operating in parallel. In general, these neurons are

Table I. The geomorphologic factors and size of landslide area of each sub-basin

\begin{tabular}{lrcccc}
\hline Location & $\begin{array}{r}\text { Creek } \\
\text { length } \\
(\mathrm{m})\end{array}$ & $\begin{array}{c}\text { Watershed } \\
\text { area } \\
\left(\mathrm{km}^{2}\right)\end{array}$ & $\begin{array}{c}\text { Slope } \\
(\text { degree })\end{array}$ & $\begin{array}{c}\text { Form } \\
\text { factor }\end{array}$ & $\begin{array}{c}\text { Landslide } \\
\text { area } \\
\left(\mathrm{m}^{2}\right)\end{array}$ \\
\hline Shou Shan & 820 & 0.64 & 21.3 & 0.95 & $6.7 \times 10^{3}$ \\
Sin An & 1500 & 1.39 & 21.3 & 0.61 & $2.1 \times 10^{4}$ \\
Sin Shan & 670 & 0.54 & 24.7 & 1.21 & $6.9 \times 10^{3}$ \\
Jyun Ping & 1260 & 0.88 & 23.3 & 0.55 & $1.7 \times 10^{4}$ \\
Jyun Keng & 1460 & 1.73 & 18.8 & 0.81 & $3.4 \times 10^{4}$ \\
Jyun An & 2380 & 1.07 & 20.3 & $0 \cdot 19$ & $2.3 \times 10^{4}$ \\
Shan An & 2680 & 2.47 & 17.2 & 0.34 & $5.9 \times 10^{4}$ \\
95.5K & 2030 & 1.64 & 24.7 & 0.4 & $4.0 \times 10^{3}$ \\
Fongciou & 1700 & 1.88 & 27.9 & 0.65 & $2.1 \times 10^{4}$ \\
Bi Shih & 1590 & 1.44 & 11.3 & 0.57 & 0 \\
Ku Keng & 870 & 1.24 & 11.9 & 1.64 & 0 \\
Wang Siang & 1990 & 1.59 & 12.9 & 0.4 & 0 \\
Siang Jiao & 2100 & 2.2 & 22.3 & 0.5 & 0 \\
Sin Sing & 2790 & 2.18 & 23.3 & 0.28 & $1.6 \times 10^{4}$ \\
Dong Pu 1 & 960 & 0.65 & 23.3 & 0.71 & 0 \\
Dong Pu 2 & 2520 & 2.54 & 26.6 & 0.4 & $5.6 \times 10^{3}$ \\
\hline
\end{tabular}

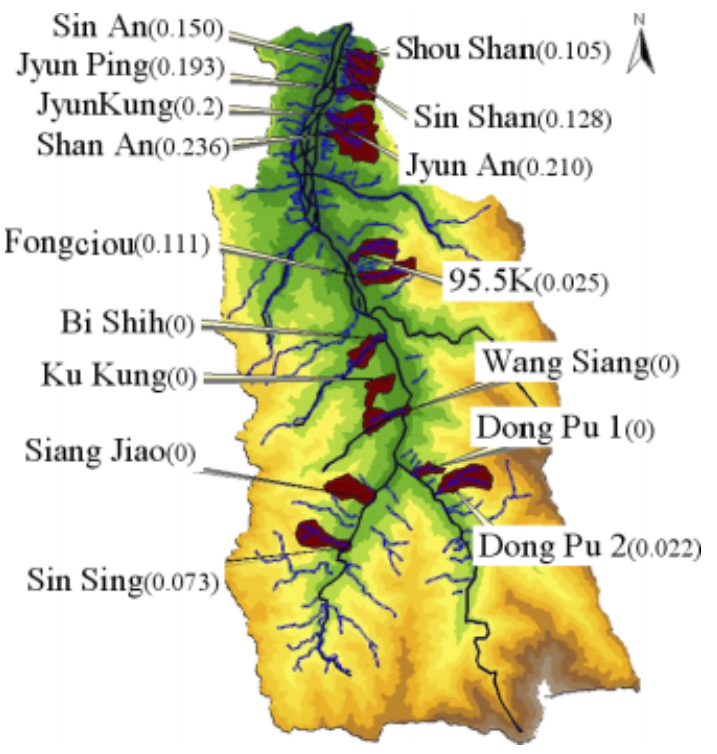

Figure 2. Area of sub-basins segmented for data analysis

arranged in the form of layers. A network usually includes three layers: (1) an input layer, (2) a hidden layer and (3) an output layer. The number of input and output neurons is always problem dependent. Neurons in the hidden or output layers receive various input information from former layer and then multiply by the connected weights. The sum of weighted inputs becomes the input for a specific transfer function that is settled in every hidden and output neuron. The network can virtually exhibit any desired output through adjusting the connected weights based on the difference between the model and target outputs. The process is known as training: The network learns the relation between input and output sequences. In practice, the ANN is especially useful for forecasting, classification, function approximation and identification problems.

The most widely used architecture of ANNs in hydrological modelling is the backpropagation neural network (BPNN), which is applied in current study. The BPNN has unique advantages such as the excellent mapping capability, fast self-learning and the ability of selfadaptation. There are many types of algorithms for training the BPNN. Basically, the purpose of training is to calculate the error at each neuron and systematically search the optimal network weights. Even if the steepest descent method is a commonly used training algorithm, it often suffers from slow convergence and sub-optimal solutions. Therefore, researchers have encouraged searching for faster and more effective algorithms. The conjugate gradient algorithm has now become more popular and widely used, since it represents a good compromise between the simplicity of the steepest descent algorithm and the fast quadratic convergence of Newton's method (Battiti, 1992). In practice, the process makes good uniform progress towards the solution at every step and has been found to be effective in finding better optimization than that of steepest descent method (Chiang et al., 2004). Based on the above description, the conjugate gradient algorithm was implemented in this study for training the 


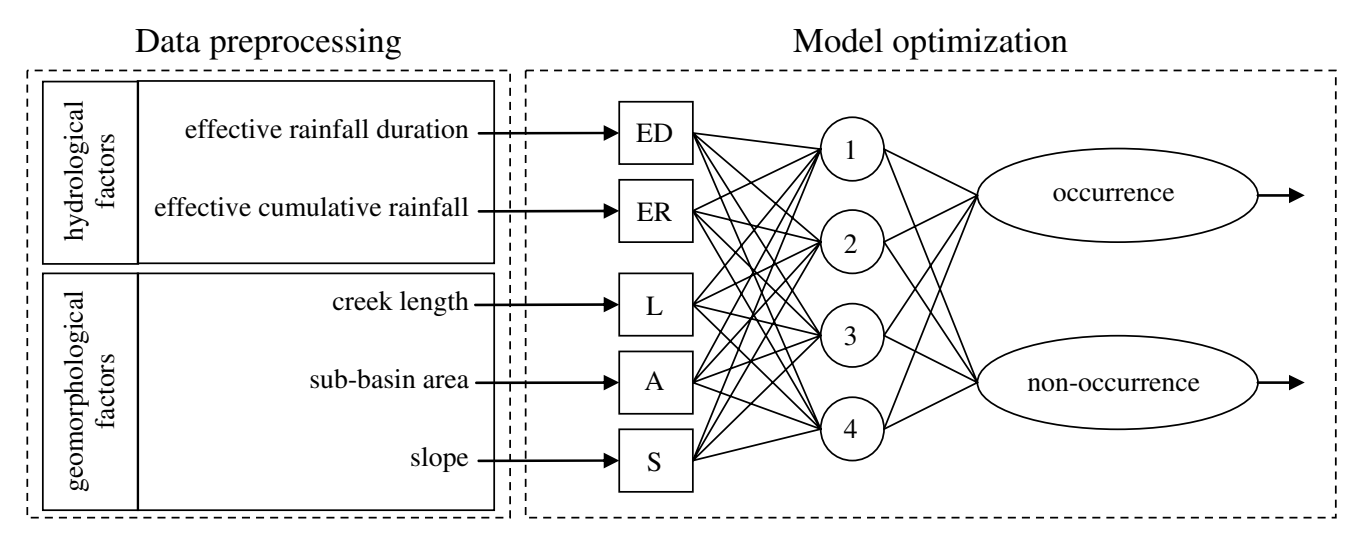

Figure 3. Architecture of the BPNN model for predicting debris flows

BPNN. Details of the conjugate gradient algorithm can be found in Ham and Kostanic (2001) and are summarized as follows.

1. The initial conjugate direction $d_{0}$ and the gain vector $g_{0}$ are defined as in the following:

$$
d_{0}=-\boldsymbol{g}_{0}=\boldsymbol{p}_{i}^{n}-\boldsymbol{C}^{n} \boldsymbol{w}_{i}^{n}(0)
$$

where $\boldsymbol{C}^{n}$ is an estimate of the covariance matrix of the inputs to the $n$th layer and $\boldsymbol{p}_{i}^{n}$ is an estimate of the crosscorrelation vector between the inputs to the $n$th layer and the desired outputs.

2. Then, the conjugate vector coefficient can be defined as follows:

$$
\alpha_{k}=-\frac{\boldsymbol{g}_{k}^{T} d_{k}}{d_{k}^{T} \boldsymbol{C} d_{k}}
$$

where $\boldsymbol{g}_{k}=\boldsymbol{C}^{n} \boldsymbol{w}_{i}^{n}(k)-\boldsymbol{p}_{i}^{n}$;

3 . The weight vector $\boldsymbol{w}$, gain vector $\boldsymbol{g}$ and conjugate gradient direction $d$ are updated as follows:

$$
\begin{aligned}
\boldsymbol{w}_{i}^{n}(k+1) & =\boldsymbol{w}_{i}^{n}(k)+\alpha_{k} d_{k} \\
\boldsymbol{g}_{k+1} & =\boldsymbol{C} \boldsymbol{w}_{i}^{n}(k+1)-\boldsymbol{p}_{i}^{n} \\
d_{k+1} & =-\boldsymbol{g}_{k+1}+\beta_{k} d_{k} ; \beta_{k}=\frac{\boldsymbol{g}_{k+1}^{T} \boldsymbol{C} d_{k}}{\boldsymbol{g}_{k}^{T} \boldsymbol{g}_{k}}
\end{aligned}
$$

Steps 2 to 3 are repeated until the errors are less than stop criterion

\section{$B P N N$ model structure and training strategy}

The model performance is highly dependent on the setting of the network structure and the optimization of its unknown parameters. Therefore, determining the numbers of input, hidden and output neurons is an important procedure. As mentioned above, the selection of input, hidden and output dimensions is problem dependent. Appropriate input variables and hidden neurons will allow the network to successfully map the desired output. To determine the appropriate number of input and hidden neurons for predicting debris flows, the trial-and-error procedure suggested by most previous works was applied.

The study collected six influence factors: ED, hourly ER, creek length $(L)$, size of sub-basin area $(A)$, slope
$(S)$ and form factor $(F)$. The strategy herein was to keep both hydrological factors, whereas the selection of geomorphologic factors is determined by trial-and-error. Finally, five variables were selected for the input layer. Three geomorphologic factors were selected except for the form factor. The results conform to previous work (Chang et al., 2007b), indicating that the impact of form factor on debris flows prediction is less than the other three geomorphologic factors in this case study. The trialand-error procedure was also used for identifying the number of hidden neurons, since no general guidelines exist for the identification of ANN structure for specific applications. The hidden neurons vary from one to ten and eventually four hidden neurons are decided. The output layer consists of two neurons representing the occurrence and non-occurrence of debris flows in next step (h). Figure 3 shows the selected architecture of the BPNN model for debris flows prediction.

To learn the impact of the earthquake on the prediction of debris flows and evaluate the BPNN model performance, two training data sets with different quality were adopted for separately optimizing the network weights. The training data set 1 consists of 620 records that were all recorded before the Chi-Chi earthquake. Amongst the 620 records, 17 records represent occurrence and 603 records present non-occurrence. The 115 records that recorded after the Chi-Chi earthquake are used as the testing data, including 21 occurrences and 94 nonoccurrences of debris flows data. The major reason for this training strategy was to investigate the influence of the earthquake on the mechanism of debris flows occurrence and the difference before and after earthquake. The samples of second training data set were randomly selected from the lump 1151 records $(1036+115)$. A total of 699 records including 30 occurrences of debris flows data were used for training the model parameters, and the remaining 452 records with 15 occurrences of debris flows data were used for testing the BPNN. Furthermore, the data pre-processing procedure is also important for the model performance. In this study, all of the collected data are normalized within the range of $(0$, 1). Prior to training, the connected weights were initialized with random values within the range of $(-1,1)$, and 


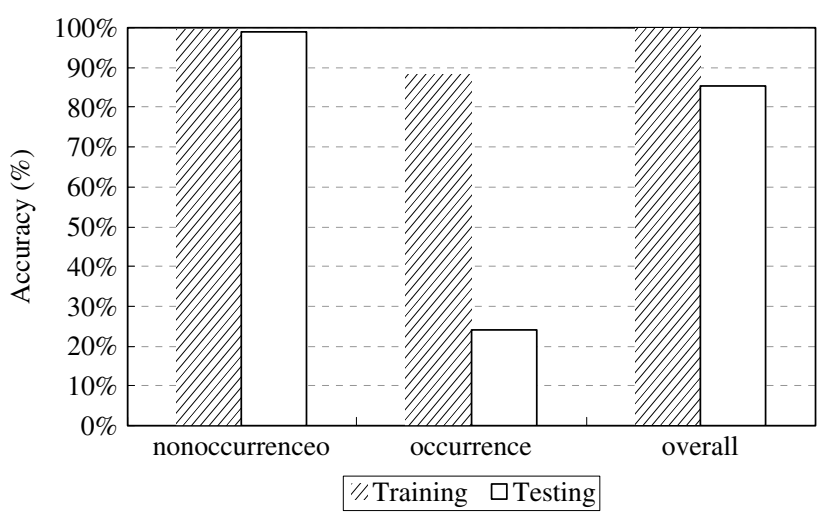

Figure 4 . The model accuracy of BPNN trained by data set 1

the stop criterion is dependent on either minimum mean squared error obtained or training iterations reached.

\section{RESULTS AND DISCUSSION}

\section{Performance of model trained with data set 1}

Figure 4 and Tables II and III show the detailed results obtained from BPNN. It should be noticed that the parameters of BPNN model are optimized by using data measured before the Chi-Chi earthquake only. The training performance on the prediction of non-occurrence is perfect with accuracy of $100 \%$ (see Table II). For the prediction of occurrence, the BPNN correctly predicts 15 out of 17 records and with an accuracy of $88 \%$. The overall training accuracy reached $99.7 \%$, which indicates that the BPNN can be well trained if sufficient data are provided. Testing results shown in Table III indicate the BPNN only predicts 5 out of 21 occurrence records even though the accuracy of non-occurrence prediction reaches $99 \%$. This is because the BPNN model learns the knowledge merely from data recorded before the Chi-Chi earthquake, and therefore it is not able to forthrightly predict the environmental status where both severe topographical and hydrological changes are encountered. These changes may result in (1) the total size of the landslide area being increased and (2) the amount of precipitation required for triggering debris flows being reduced.

As far as the above effects are concerned, both changes are related to the reduction of ER. Hence, a correction on this hydrological input factor was made without changing the model architecture. The equation is as follows.

$$
E R_{\mathrm{R}}=E R_{\mathrm{O}}+R_{\mathrm{L}}+c
$$

where $E R_{\mathrm{R}}$ and $E R_{\mathrm{O}}$ represent the normalized revised and original ER, respectively; $R_{\mathrm{L}}$ represents the ratio of landslide area to sub-basin area; and $c$ represents a constant that reflects the amount of precipitation required for triggering debris flows was reduced.

Since no general guidelines exist for the identification of the constant, the trial-and-error procedure was again used for determining the constant $c$. The value of $c$ was tested from 0 and stepped by $0 \cdot 1$ in this study. It is interesting that the overall accuracy is $87.8 \%$ (occurrence prediction: 8/21, non-occurrence prediction: $93 / 94$ and overall: 101/115) when the value of $c$ is 0 , which means the information added to the input factor is only the landslide area. As compared with the results in Table III, the accuracy of the model outputs for the occurrence of debris flows prediction has increased, indicating that the probability of the occurrence of debris flows was actually affected by the landslide area. Moreover, the optimal value for the constant is $0 \cdot 1$ with occurrence prediction: 13/21, non-occurrence prediction: 90/94 and overall: 103/115 (89.6\%), which resulted in an increase of $4 \%$ in terms of overall accuracy and strongly enhanced the occurrence of debris flows prediction from 5 records to 13 records as compared with results in Table III.

Table II. Training results of the BPNN trained by data set 1

\begin{tabular}{lccrr}
\hline Training & \multicolumn{2}{c}{ Model outputs } & Accuracy (\%) \\
\cline { 3 - 5 } & Non-occurrence & Occurrence & \\
\hline Observations & Non-occurrence & 603 & 0 & 100 \\
& Occurrence & 2 & 15 & 88 \\
\hline
\end{tabular}

Note: The italicized values indicate the numbers of correct predictions.

Table III. Testing results of the BPNN trained by data set 1

\begin{tabular}{|c|c|c|c|c|}
\hline \multirow[t]{2}{*}{ Testing } & & \multicolumn{2}{|c|}{ Model outputs } & \multirow[t]{2}{*}{ Accuracy $(\%)$} \\
\hline & & Non-occurrence & Occurrence & \\
\hline \multirow[t]{2}{*}{ Observations } & Non-occurrence & 93 & 1 & 99 \\
\hline & Occurrence & 16 & 5 & 24 \\
\hline
\end{tabular}

Note: The italicized values indicate the numbers of correct predictions. 


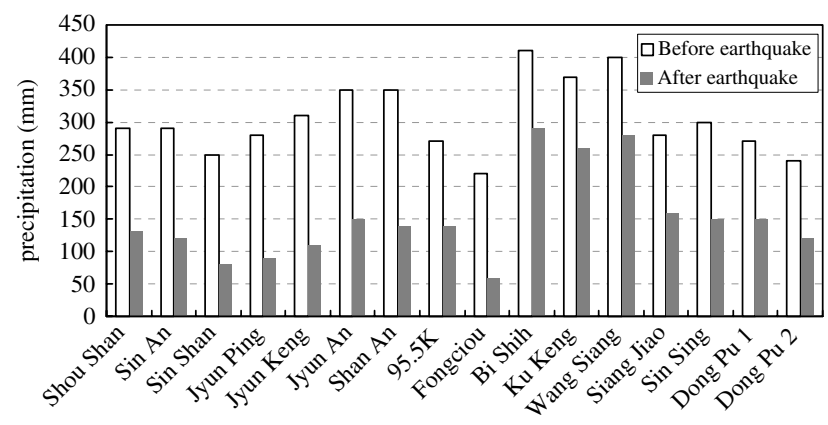

Figure 5. The critical rainfall for triggering debris flows in each sub-basin

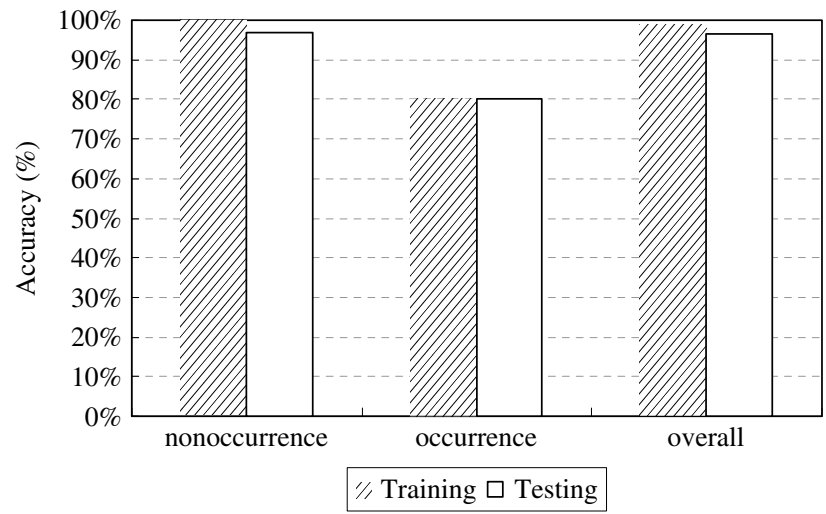

Figure 6. The model accuracy of BPNN trained by data set 2

Results obtained above demonstrated an important fact that the landslide phenomenon did contribute to the soil and rock deposits, and therefore accelerated the occurrence of debris flows. Besides, the requirement of quantity for rainfall-induced debris flows was reduced over this region. The critical rainfall for triggering debris flows in each sub-basin after the Chi-Chi earthquake has been calculated as shown in Figure 5. Basically, the critical rainfall required to touch off debris flows has been reduced at least $110 \mathrm{~mm}$ than that of before. The results are similar to that of Lin et al. (2004) and imply the debris flows may occur not only during torrential storm or typhoon events but also light rains. Inspection of Figure 5 clearly indicates about 10 sub-basins where debris flows occurred with less than half the rainfall that caused debris flows before the Chi-Chi earthquake.

\section{Performance of model trained with data set 2}

Figure 6 and Tables IV and V illustrate the performance of BPNN outputs that model parameters are retrained with data set 2 . Similarly, the training performance on the prediction of non-occurrence is almost perfect, which only has one incorrect record and the overall accuracy of training reaches $99 \cdot 1 \%$. Furthermore, the testing results displayed in Table $\mathrm{V}$ show that the outcome of occurrence prediction is exciting with an accuracy of $80 \%$ even though the testing samples consisted of data observed before and after the Chi-Chi earthquake. By retraining the BPNN, the overall accuracy in the testing phase increased from 85.3 to $96.5 \%$ (see Tables III and $\mathrm{V})$. Particularly, the accuracy of occurrence prediction strongly increased from 24 to $80 \%$. The results demonstrated that the BPNN is capable of learning the complex mechanism of debris flows events and producing satisfactory predictions.

In fact, there are five occurrence records obtained from two locations that cannot be identified no matter whether the data are arranged in training or testing phases. Table VI shows these five data and their corresponding ER. It is surprising that the amount of rainfall for triggering debris flows is much less (under $45 \mathrm{~mm}$ ) than the critical values (Figure 5). Before the Chi-Chi earthquake, the rainfall required for causing debris flows was $220 \mathrm{~mm}$ and $300 \mathrm{~mm}$ over Fongciou and Sin Sing areas, respectively. However, the truth is that the debris flows now can occur with only less than one fourth of the original critical rainfall. This means that the deposits resulting from a landslide over these areas are quite loose and unstable and debris flows can be initiated with a small amount of rainfall. Furthermore, before the earthquake, the recurrence time of a debris flow in this area was greater than 5 years, whereas these five records occurred within 15 months since the earthquake. Hence, further investigation on the variations of debris flows and their mechanism over the watershed is required.

\section{CONCLUSIONS}

The study area, Chen-Yu-Lan river watershed, possesses three essential factors in the occurrence of debris flows: sufficient rainfall, sufficient deposits and sufficient slope. In the aftermath of the destructive Chi-Chi earthquake on 21st September, 1999, the study area was further devastated by enormous debris flows that are likely to strike the same region in the future. Therefore, an effective and accurate debris flow warning system is extremely important to provide time for rescuing human life and property. The present study investigated the

Table IV. Training results of the BPNN trained by data set 2

\begin{tabular}{lcccc}
\hline Training & \multicolumn{2}{c}{ Model outputs } & Accuracy (\%) \\
\cline { 3 - 5 } & & Non-occurrence & Occurrence & \\
\hline Observations & Non-occurrence & 668 & 1 & 99.9 \\
& Occurrence & 6 & 24 & 80 \\
& Overall accuracy $=692 / 699=99.1 \%$ & & \\
\hline
\end{tabular}

Note: The italicized values indicate the numbers of correct predictions. 
Table V. Testing results of the BPNN trained by data set 2

\begin{tabular}{|c|c|c|c|c|}
\hline \multirow[t]{2}{*}{ Testing } & & \multicolumn{2}{|c|}{ Model outputs } & \multirow[t]{2}{*}{ Accuracy $(\%)$} \\
\hline & & Non-occurrence & Occurrence & \\
\hline \multirow[t]{2}{*}{ Observations } & $\begin{array}{l}\text { Non-occurrence } \\
\text { Occurrence }\end{array}$ & $\begin{array}{r}424 \\
3\end{array}$ & $\begin{array}{l}13 \\
12\end{array}$ & $\begin{array}{l}97 \\
80\end{array}$ \\
\hline & \multicolumn{3}{|c|}{ Overall accuracy $=436 / 452=96 \cdot 5 \%$} & \\
\hline
\end{tabular}

Note: The italicized values indicate the numbers of correct predictions.

earthquake's impact on the mechanism of the occurrence of debris flows and constructed a reliable ANN model for debris flows prediction. To construct a stable and reliable model for accurately predicting debris flows in the Chen-Yu-Lan river watershed, six factors related to its occurrence were chosen in terms of geomorphologic and hydrological influences.

Two training data sets, i.e. (1) before the Chi-Chi earthquake and (2) lumped before and after the earthquake, were given for calibrating the BPNN parameters. Performance from model trained with data set 1 indicated that the Chi-Chi earthquake significantly changed both topographical and hydrological conditions that resulted in the debris flows that have frequently occurred over this area. It was also shown that the consideration of landslide area as additional input information effectively increased the accuracy of BPNN predictions. Another important finding is that after the earthquake, the critical rainfall for initiating debris flows was reduced to about half of original critical rainfall. Results obtained from a model trained with data set 2 demonstrated that the constructed BPNN model was capable of learning the complex mechanism of debris flows events. The overall accuracy in testing phase reached $96.5 \%$, including an accuracy of $97 \%$ for non-occurrence predictions and an accuracy of $80 \%$ for occurrence predictions. Therefore, the present model has been proven to successfully predict both occurrence and non-occurrence of debris flows.

The condition that triggers debris flow changes gradually as time passes after the earthquake. Before the ChiChi earthquake, the typhoon-induced debris flows only occur when the typhoons accompany huge amount of rainfall, whereas the debris flows could easily occur after earthquake even though the rainfall is not heavy. The accumulation of rainfall for triggering debris flows has abnormally reduced, and the amount of deposits and size of landslide area are likely proportional to the probability of debris flows occurrences. As time passes, if there are

Table VI. Date and effective cumulative rainfall of unpredictable records

\begin{tabular}{lcc}
\hline Location & Effective cumulative rainfall $(\mathrm{mm})$ & Date \\
\hline Fongciou & $43 \cdot 2$ & 1.5 .2000 \\
Fongciou & 44.4 & 20.7 .2001 \\
Sin Sing & 39.9 & 28.4 .2000 \\
Sin Sing & $27 \cdot 4$ & 2.5 .2000 \\
Sin Sing & $36 \cdot 5$ & 20.7 .2001 \\
\hline
\end{tabular}

no more deposits resulted from landslide or earthquake, the amount of deposits will gradually reduce until the deposits are insufficient to form a debris flow. The topographical condition of the watershed will also gradually stabilize to that of before earthquake. Consequently, retraining the model with updating input variables is more suitable for predicting debris flows within a short period after earthquake.

\section{REFERENCES}

Ayalew L, Yamagishi H. 2005. The application of GIS-based logistic regression for landslide susceptibility mapping in the Kakuda-Yahiko Mountains, Central Japan. Geomorphology 65(1-2): 15-31.

Battiti R. 1992. 1st-order and 2nd-order methods for learning-between steepest descent and Newton method. Neural Computation 4(2): $141-166$.

Chang FJ, Chiang YM, Chang LC. 2007a. Multi-step-ahead neural networks for flood forecasting. Hydrological Sciences Journal-Journal Des Sciences Hydrologiques 52(1): 114-130.

Chang FJ, Tseng KY, Chaves P. 2007b. Shared near neighbours neural network model: a debris flow warning system. Hydrological Processes 21(14): 1968-1976.

Chang TC, Chao RJ. 2006. Application of back-propagation networks in debris flow prediction. Engineering Geology 85(3-4): 270-280.

Chiang YM, Chang FJ, Jou BJD, Lin PF. 2007a. Dynamic ANN for precipitation estimation and forecasting from radar observations. Journal of Hydrology 334(1-2): 250-261.

Chiang YM, Chang LC, Chang FJ. 2004. Comparison of staticfeedforward and dynamic-feedback neural networks for rainfall-runoff modeling. Journal of Hydrology 290(3-4): 297-311.

Chiang YM, Hsu KL, Chang FJ, Hong Y, Sorooshian S. 2007b. Merging multiple precipitation sources for flash flood forecasting. Journal of Hydrology 340(3-4): 183-196.

Dawson CW, Wilby R. 1998. An artificial neural network approach to rainfall-runoff modelling. Hydrological Sciences Journal-Journal Des Sciences Hydrologiques 43(1): 47-66.

Fedora MA, Beschta RL. 1989. Storm runoff simulation using an antecedent precipitation index (Api) model. Journal of Hydrology 112(1-2): $121-133$.

French MN, Krajewski WF, Cuykendall RR. 1992. Rainfall forecasting in space and time using a neural network. Journal of Hydrology 137(1-4): $1-31$.

Ham FM, Kostanic I. 2001. Principles of Neurocomputing for Science and Engineering. McGraw Hill: New York.

Kanungo DP, Arora MK, Sarkar S, Gupta RP. 2006. A comparative study of conventional, ANN black box, fuzzy and combined neural and fuzzy weighting procedures for landslide susceptibility zonation in Darjeeling Himalayas. Engineering Geology 85(3-4): 347-366.

Lee S, Ryu JH, Kim IS. 2007. Landslide susceptibility analysis and its verification using likelihood ratio, logistic regression, and artificial neural network models: case study of Youngin, Korea. Landslides 4(4): 327-338.

Lin CW, Liu SH, Lee SY, Liu CC. 2006. Impacts of the Chi-Chi earthquake on subsequent rainfall-induced landslides in central Taiwan. Engineering Geology 86(2-3): 87-101.

Lin CW, Shieh C-L, Yuan B-D, Shieh Y-C, Liu S-H, Lee S-Y. 2004. Impact of Chi-Chi earthquake on the occurrence of landslides and debris flows: example from the Chenyulan River watershed, Nantou, Taiwan. Engineering Geology 71(1-2): 49-61. 
Lin ML, Jeng FS. 2000. Characteristics of hazards induced by extremely heavy rainfall in Central Taiwan-Typhoon Herb. Engineering Geology 58(2): 191-207.

Lin PS, Lin JY, Hung JC, Yang MD. 2002. Assessing debris-flow hazard in a watershed in Taiwan. Engineering Geology 66(3-4): 295-313.

Liu KF, Huang MC. 2006. Numerical simulation of debris flow with application on hazard area mapping. Computational Geosciences 10(2): 221-240.

Lu GY, Chiu LS, Wong DW. 2007. Vulnerability assessment of rainfall-induced debris flows in Taiwan. Natural Hazards 43(2): 223-244.

Nagy HM, Watanabe K, Hirano M. 2002. Prediction of sediment load concentration in rivers using artificial neural network model. Journal of Hydraulic Engineering-ASCE 128(6): 588-595.

Pavel M, Fannin RJ, Nelson JD. 2008. Replication of a terrain stability mapping using an artificial neural network. Geomorphology 97(3-4): $356-373$.
Vanacker V, Vanderschaeghe M, Govers G, Willems E, Poesen J, Deckers J, De Bievre B. 2003. Linking hydrological, infinite slope stability and land-use change models through GIS for assessing the impact of deforestation on slope stability in high Andean watersheds. Geomorphology 52(3-4): 299-315.

Wan S, Lei TC, Huang PC, Chou TY. 2008. The knowledge rules of debris flow event: a case study for investigation Chen Yu Lan river, Taiwan. Engineering Geology 98(3-4): 102-114.

Wen BP, Aydin A. 2005. Mechanism of a rainfall-induced slide-debris flow: constraints from microstructure of its slip zone. Engineering Geology 78(1-2): 69-88.

Zealand CM, Burn DH, Simonovic SP. 1999. Short term streamflow forecasting using artificial neural networks. Journal of Hydrology 214(1-4): 32-48. 